\title{
Bean and rice meals reduce postprandial glycemic response in adults with type 2 diabetes: a cross-over study
}

\author{
Sharon V Thompson ${ }^{1}$, Donna M Winham ${ }^{2 *}$ and Andrea M Hutchins ${ }^{3}$
}

\begin{abstract}
Background: Around the world, beans and rice are commonly consumed together as a meal. With type 2 diabetes increasing, the effect of this traditional diet pattern on glycemic response has not been studied fully.

Methods: We evaluated the glycemic response of bean and rice traditional meals compared to rice alone in adults with type 2 diabetes. Seventeen men and women with type 2 diabetes controlled by metformin $(n=14)$ or diet/exercise $(n=3)$ aged $35-70$ years participated in the randomized $4 \times 4$ crossover trial. The white long grain rice control, pinto beans/rice, black beans/rice, red kidney beans/rice test meals, matched for 50 grams of available carbohydrate, were consumed at breakfast after a 12 hour fast. Capillary blood glucose concentrations at baseline and at 30 minute intervals up to 180 minutes postprandial were collected. MANOVA for repeated measures established glucose differences between treatments. Paired $t$ tests identified differences between bean types and the rice control following a significant MANOVA.
\end{abstract}

Results: Postprandial net glucose values were significantly lower for the three bean/rice treatments in contrast to the rice control at 90,120 and 150 minutes. Incremental area under the curve values were significantly lower for the pinto and black bean/rice meals compared to rice alone, but not for kidney beans.

Conclusions: Pinto, dark red kidney and black beans with rice attenuate the glycemic response compared to rice alone. Promotion of traditional foods may provide non-pharmaceutical management of type 2 diabetes and improve dietary adherence with cultural groups.

Trial registration: Clinical Trials number NCT01241253

Keywords: Beans, Type 2 diabetes, Traditional diets, Glycemic response

\section{Background}

Phaseolus vulgaris species such as pinto, black and dark red kidney beans with white rice are classic food combinations in many areas of the world, especially in the Caribbean, Latin America, Middle East, and Mediterranean [1]. Epidemiological studies show associations with increased bean consumption and decreased rates/ prevalence of chronic diseases including type 2 diabetes [1-3]. In the United States, the Centers for Disease Control estimate that 25.8 million people, or approximately $8 \%$ of the population, have type 2 diabetes mellitus [4]. A

\footnotetext{
* Correspondence: dmwinham@howellreserearch.org

${ }^{2}$ Howell Research Associates, LLC, P.O. Box 1010, Queen Creek, AZ 85142. USA

Full list of author information is available at the end of the article
}

disproportionate number of Hispanics (11.8\%) and African Americans (12.6\%) are affected by this disease [4].

Diet and lifestyle changes are the first intervention steps recommended by leading health agencies to prevent and control type 2 diabetes [5,6]. Despite the known benefits of diet and lifestyle change, there is often poor adherence to dietary recommendations [7-10]. In fact, difficulty meeting diabetic dietary guidelines is a frequently reported concern [10], particularly among Hispanic [11-14] and African American type 2 diabetes populations $[15,16]$. Two adherence barriers often mentioned are exclusion of culturally familiar foods from counseling and diet education materials and the perceived inability to eat the same foods as the rest of the family, e.g. beans and rice $[11,12,16]$.

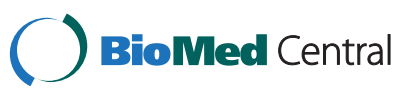

end of the article

(c) 2012 Thompson et al; BioMed Central Ltd. This is an Open Access article distributed under the terms of the Creative Commons Attribution License (http://creativecommons.org/licenses/by/2.0), which permits unrestricted use, distribution, and reproduction in any medium, provided the original work is properly cited. 
Beans are known functional foods that are low in fat and high in fiber, vegetable protein, folate, iron, magnesium, zinc, omega-3 fatty acids, and antioxidants [1-3]. They also contain phytate and phenolic compounds that may function in similar ways to $\alpha$-glucosidase or $\alpha$-amylase inhibitor type 2 diabetes medications like the oral hypoglycemic agent acarbose [17].

Beans have a low glycemic index (GI) which by definition means they produce a relatively low rise in blood glucose after a meal [17-19]. In contrast, high GI items like long grain white rice can cause postprandial glycemic elevations that are damaging to vascular tissues and other organs $[20,21]$. Regular white rice consumption has also been linked to an increased risk of type 2 diabetes [22]. Few studies have looked at the acute effects of $P$. vulgaris or common beans on glycemic response as part of traditional meals or in combination with other foods $[17,19,20,23]$.

Since elevated blood glucose is a significant contributor to cardiovascular risk, these findings have important implications for chronic disease risk reduction beyond type 2 diabetes [5,21]. Emphasizing the continued inclusion of culturally familiar beans in the therapeutic diets of persons with type 2 diabetes may decrease postprandial glycemic variability, maintain vascular health, and improve dietary compliance and thus quality of life, especially for immigrants and minorities [9-11,24]. We hypothesized that pinto, black, and dark red kidney beans in combination with long grain white rice would equally reduce postprandial glycemic response in adults with type 2 diabetes.

\section{Methods}

\section{Study population}

Adults aged 35-70 years old with type 2 diabetes managed by metformin or diet/exercise were recruited to participate in the $4 \times 4$ randomized cross-over trial. Persons using insulin or other diabetic drugs were excluded to minimize potential confounding from multiple hypoglycemic medications with various modes of action. All participants were physician-diagnosed with type 2 diabetes at least 6 months prior to starting the study. The method of diabetes management had to be the same for at least 3 months prior to study entry. Eligible participants had a hemoglobin A1c (HbA1c) value of $<10 \%$ at screening and had no evidence of condition(s) that would influence their ability to complete the study as determined from medical record analysis. Those with weight changes $+/-5 \mathrm{~kg}$ within 6 months, women who were either pregnant or breastfeeding, and individuals with allergy to beans or latex were excluded during the screening process. This study was approved by the University Institutional Review Board, and all participants provided written, informed consent.

Twenty-eight individuals with type 2 diabetes enrolled in the study. Twenty-one successfully completed the study in its entirety. Four participants were excluded from final analysis. Three of the latter participants did not fully disclose medical conditions until after they started the study and were ineligible. An additional participant was noncompliant with the pre-test date dietary protocol (See consort diagram, Figure 1). Data from 17 individuals ( 9 men and 8 women) aged 38-70 years were analyzed (Table 1). Fourteen of these individuals used the medication metformin to manage their type 2 diabetes, while the other three used dietary methods and/or physical activity.

\section{Study design}

Participants were administered four different test meals separated by one week in this $4 \times 4$ randomized crossover study (ClinicalTrials.gov: NCT01241253). At the time of study consent, participants selected a commercial frozen meal, e.g. Lean Cuisine or Marie Callender's brands. They consumed the same frozen meal for each of the four pretest evening meals at the same time each evening, in order to reduce any variation in morning glycemic response due to the Second Meal Effect [18,25]. Participants were also given instructions for completing a 24-hour dietary recall for each day before testing and were told to refrain from consuming any alcohol, caffeine or taking part in any physical activity beyond that of their typical daily activities during this time. After consuming the provided meal on the eve of testing, participants drank only water until they arrived at the study location 12 hours later. Upon arrival at the test site, 24-hour dietary recall forms were reviewed by a nutritionist, and participants were confirmed fasting and compliant with study procedures. They were then weighed using a digital scale (Seca Model 880, Hamburg, Germany). Standing height was assessed at the first test day meeting using a wall-mounted stadiometer (SECA, Ontario, CA). Next, a fasting capillary blood sample $(\sim 100 \mu \mathrm{l})$ was collected from a fingerstick using Safe-TFill $^{\circledR}$ Lithium Heparin Mini Capillary Collection centrifuge tubes (RAM Scientific, Yonkers, NY). After fasting blood sample collection, participants consumed one of the four bean and white rice test meal options within 5-10 minutes under researcher supervision. Whole blood glucose concentrations were analyzed at baseline and at 30, 60, 90, 120, 150, and 180 minutes post-treatment using a Yellow Springs Instrument 2500 Stat Plus Analyzer (YSI Life Sciences, Yellow Springs, OH). All blood analyses were completed immediately after collection.

\section{Test meals}

Participants received the four test meals in random order. Excel software was used to generate randomization sequences prior to participant recruitment by DMW (Microsoft, Redmond, WA). Three meals included one of the commercially canned $P$. vulgaris market classes: pinto 


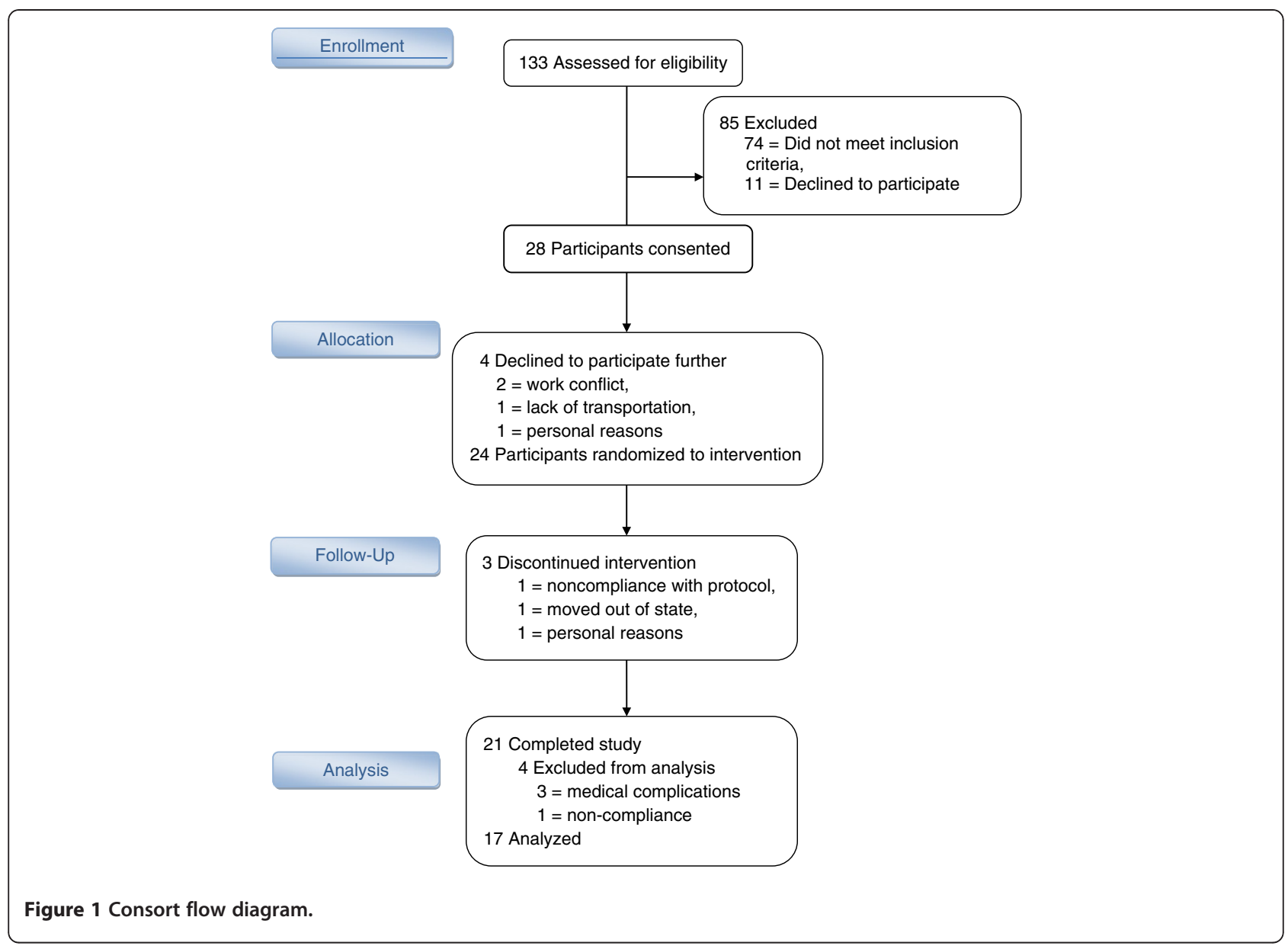

beans, black beans or dark red kidney beans (Bush Brothers \& Company) along with $\sim 1 / 2$ cup of white long grain rice (Great Value brand, Walmart). A control meal containing 180 grams or approximately $7 / 8$ cup of steamed long grain white rice was included as the fourth meal. Long grain

Table 1 Baseline characteristics of study participants $(n=17)$

\begin{tabular}{lll}
\hline Variable & Mean \pm SEM & Range \\
\hline Age $(\mathrm{y})$ & $58.6 \pm 2.3$ & $(38-70)$ \\
Weight $(\mathrm{kg})^{1}$ & $93.4 \pm 4.0$ & $(67.8-120.9)$ \\
Height $(\mathrm{cm})^{1}$ & $170.7 \pm 2.1$ & $(154.4-184.5)$ \\
$\mathrm{BMI}\left(\mathrm{kg} / \mathrm{m}^{2}\right)^{1}$ & $31.9 \pm 1.0$ & $(26.9-38.8)$ \\
$\mathrm{TC}(\mathrm{mg} / \mathrm{dL})$ & $172.9 \pm 7.5$ & $(119.0-220.0)$ \\
$\mathrm{TG}(\mathrm{mg} / \mathrm{dL})$ & $156.4 \pm 18.8$ & $(68.0-328.0)$ \\
$\mathrm{HDL}-\mathrm{C}(\mathrm{mg} / \mathrm{dL})$ & $44.4 \pm 1.9$ & $(36.0-65.0)$ \\
$\mathrm{LDL}-\mathrm{C}(\mathrm{mg} / \mathrm{dL})$ & $98.9 \pm 5.6$ & $(59.0-133.0)$ \\
$\mathrm{HbA1c}(\%)$ & $6.5 \pm 0.1$ & $(5.8-7.8)$ \\
\hline
\end{tabular}

${ }^{1}$ Values obtained at study entry. BMI = body mass index, TC= total cholesterol, $\mathrm{TG}=$ triglycerides, $\mathrm{HDL}-\mathrm{C}=$ high density lipoprotein cholesterol, $\mathrm{LDL}-\mathrm{C}=$ low density lipoprotein cholesterol, $\mathrm{HbA} 1 \mathrm{c}=$ hemoglobin A1c. white rice has been found to have an average GI value of $80 \pm 3$ across ten studies and is considered to be a high GI food $[20,26,27]$. Black beans (GI value 20), pinto beans (GI value 45), and red kidney beans (GI value 20) are considered to be low GI foods [26,27]. Nutrient composition of test meals is provided in Table 2. The amount of beans was standardized to provide 50 grams of available carbohydrate $(\mathrm{CHO})$ while the gram weight of white rice was kept constant. Available $\mathrm{CHO}$ was calculated by subtracting the dietary fiber from the total $\mathrm{CHO}$ value listed on the manufacturer's nutrition facts label $[25,28,29]$. Fifty grams of $\mathrm{CHO}$ is a standard amount used to test glucose response among persons with and without type 2 diabetes [19,30,31].

White rice was prepared in an electric automatic rice cooker based on the manufacturer's instructions (Black \& Decker RC400, Miami Lakes, FL). Rice and water amounts were standardized to gram weights for preparation consistency. Proportions of $945 \mathrm{~g}$ of bottled drinking water was added to $420 \mathrm{~g}$ of dry white rice and steamed for $\sim 30$ minutes. The canned beans (Bush Brothers \& Company) were drained, but not rinsed, and heated in a microwave for 1 minute at medium power. The test meal 
Table 2 Descriptive characteristics of test meals ${ }^{1}$

\begin{tabular}{lllll}
\hline Characteristics & $\begin{array}{l}\text { White } \\
\text { rice } \\
\text { control }\end{array}$ & $\begin{array}{l}\text { Pinto } \\
\text { beans and } \\
\text { white rice }\end{array}$ & $\begin{array}{l}\text { Black beans } \\
\text { and white } \\
\text { rice }\end{array}$ & $\begin{array}{l}\text { Kidney } \\
\text { beans and } \\
\text { white rice }\end{array}$ \\
\hline Total weight (g) & 180.0 & 305.0 & 243.0 & 267.0 \\
Rice (g) & 180.0 & 128.0 & 128.0 & 128.0 \\
Beans (g) & - & 177.0 & 115.0 & 139.0 \\
Energy (kcal) & 232.0 & 273.9 & 257.9 & 277.2 \\
$\begin{array}{l}\text { Total carbohydrate } \\
\text { (g) }\end{array}$ & 49.5 & 59.7 & 55.5 & 58.7 \\
$\begin{array}{l}\text { Available } \\
\text { CHO (g) }\end{array}$ & 48.8 & 49.7 & 49.7 & 49.7 \\
Rice (g) & 48.8 & 34.7 & 34.7 & 34.7 \\
Beans (g) & - & 15.0 & 15.0 & 15.0 \\
Fiber (g) & 0.7 & 10.0 & 5.8 & 9.1 \\
Protein (g) & 4.8 & 11.6 & 9.6 & 10.9 \\
Fat (g) & 0.5 & 0.4 & 0.8 & 0.4 \\
\hline
\end{tabular}

${ }^{1}$ Nutrition information was obtained from the food's Nutrition Facts Label; Great Value (rice) and Bush Brothers \& Company (beans).

was prepared by weighing out the cooked rice in a serving bowl, then adding the appropriate weight of warmed beans, and 15 grams of the drained can liquid for moisture. The digital scale was tared to zero to account for the serving bowl, then again after addition of each food item (Salter, Fairmont, MN).

\section{Statistical analysis}

SPSS Statistics software version 18.0 (IBM Corporation, Somers, NY) was used for statistical analyses. The level of significance was $P \leq 0.05$. Independent $t$ tests were used to analyze data by gender and type 2 diabetes treatment type. Time point differences between fasting and post-treatment glucose concentrations were determined and incremental area under the curve (iAUC) calculations were completed using the trapezoidal rule (Table 3) [32]. The iAUC for blood glucose was assessed between 0-60, 0-120, and 0-180 minutes postprandial for all participants. Multivariate analysis of variance (MANOVA) for repeated measures with time and diet as factors was used to establish differences between the four meal treatments. Effect sizes were also calculated and interpreted using Cohen's classifications
[33]. Following a significant MANOVA, paired $t$ tests were used to identify differences between specific bean treatments and the rice control. All continuous variable data are reported as mean \pm standard error.

\section{Results}

Descriptive statistics at study entry for the 17 participants are shown in Table 1 . The majority of the participants were White (82\%) and non-Hispanic (94\%). Participants were also, on average, classified as obese according to their BMI values $\left(31.8 \pm 1.0 \mathrm{~kg} / \mathrm{m}^{2}\right)$. Body weight and body mass index (BMI) did not significantly differ between test days. Data were analyzed by gender and treatment type and no significant differences were seen with regard to descriptive statistics, time point glucose differences or iAUC values, so data were subsequently pooled for analysis. Time point differences in glucose concentrations were found to be significantly lower at 90 minutes postprandial for the pinto beans and rice $(P=0.011)$, black beans and rice $(P=0.004)$, and red kidney beans and rice $(P=0.040)$ as compared with the white rice control meal. Similar results were seen at 120 minutes $(P=0.000,0.001$ and 0.026 for the pinto beans, black beans, and red kidney beans respectively) and 150 minutes postprandial $(P=0.000,0.002$, and 0.0049) (Figure 2). The 90 minute glucose difference had an effect size of 0.469 . Medium effect sizes found at the 120 and 150 minute glucose timepoints, which were 0.634 and 0.554 , respectively. The iAUC for blood glucose were assessed between 0-60, 0-120 and 0-180 minutes postprandial for all participants. Significant differences were found between the rice control meal and the pinto beans and rice and black beans and rice at $0-120(P=0.009$ and 0.002$)$ and $0-180$ minutes $(P=0.017$ and 0.007$)$. The effect sizes (Cohen's d) for iAUC were determined to be 0.431 for $0-120$ minutes and 0.501 for $0-180$ minutes.

\section{Discussion}

Our study found bean and rice meals produce an attenuated glucose response in comparison to rice alone in equal available $\mathrm{CHO}$ treatments. These results reinforce those of the few existing previous studies showing intermediate responses with mixed meals of high and low GI

Table 3 Postprandial areas under the curve for blood glucose $(n=17)^{1,2,3}$

\begin{tabular}{lllll}
\hline & White rice control & $\begin{array}{l}\text { Pinto beans and } \\
\text { white rice }\end{array}$ & $\begin{array}{l}\text { Black beans and } \\
\text { white rice }\end{array}$ & $\begin{array}{l}\text { Kidney beans and } \\
\text { white rice }\end{array}$ \\
\hline 0-60 min & $2763.2 \pm 170.0$ & $2509.5 \pm 199.0$ & $2598.0 \pm 181.8$ & $2695.1 \pm 199.0$ \\
$0-120 \mathrm{~min}$ & $6254.0 \pm 448.0$ & $5246.2 \pm 409.9^{* *}$ & $5369.2 \pm 409.6^{*}$ & $5748.6 \pm 420.1$ \\
$0-180 \mathrm{~min}$ & $7436.8 \pm 622.4$ & $5789.4 \pm 488.7^{* *}$ & $5991.6 \pm 510.7^{* *}$ & $6625.4 \pm 534.6$ \\
\hline
\end{tabular}

\footnotetext{
${ }^{1}$ All values are means \pm standard error of the mean (SEM).

${ }^{2} \mathrm{Mg} * \mathrm{~min} / \mathrm{dL}$ (calculated by the trapezoidal rule).

${ }^{3}$ For variables in which the treatment $x$ AUC interaction was significant, paired $t$ tests were conducted to assess within-group change.

${ }^{*} P<0.05$, ** $P<0.01$.
} 


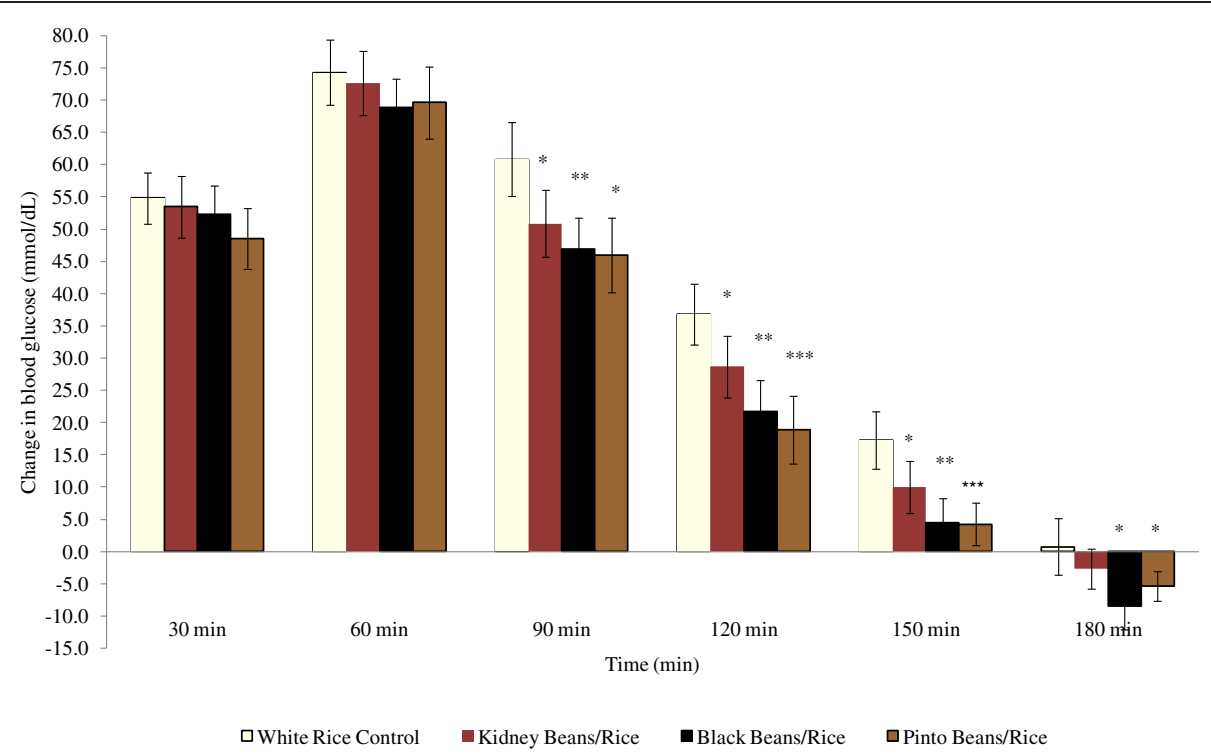

Figure 2 Influence of treatments on postprandial net glucose $(\boldsymbol{n}=\mathbf{1 7})^{\mathbf{1}}$. Figure Legend: $\square$ White Rice; $\square$ Kidney Beans/Rice; Black Beans/ Rice; $\square$ Pinto Beans/Rice. ${ }^{1}$ All values are means \pm standard error of the mean (SEM). ${ }^{*} P<0.05$, ${ }^{* *} P<0.01$, ${ }^{* * *} P<0.001$.

foods. More importantly, our findings specifically demonstrate this response with traditional bean and rice combinations that are consumed widely around the world. An intermediate response is favorable to the higher response produced by white rice alone, and may help prevent the detrimental effects of prolonged glycemic elevations. Prolonged elevated glucose levels contribute to the well-known macrovascular (cardiovascular disease, peripheral vascular disease) and microvascular (nephropathy, retinopathy, neuropathy) complications associated with type 2 diabetes. Attenuating postprandial glucose changes by encouraging people with type 2 diabetes to combine traditional high GI food like rice with beans could perhaps contribute to a lower risk for the complications associated with type 2 diabetes. Also worthy of note is that all study treatments reduced the average 2 hour postprandial glucose below $140 \mathrm{mg} / \mathrm{dl}$, which is a recommended glycemic control goal by the International Diabetes Federation [34]. This also suggests that our participants had well controlled type 2 diabetes.

P. vulgaris beans such as those included in this study (pinto, black and dark red kidney beans) along with white rice are a traditional food combination consumed by many in the U.S. and around the world, particularly those in Latin America and countries within the Mediterranean and Middle East. As this study demonstrates, counseling patients to exclude cultural foods like the bean and rice combination may be unwarranted for persons with type 2 diabetes. Jimenez-Cruz et al. also found that traditional Mexican foods like corn tortillas and pinto beans had a low GI, were satiating, and improved glycemic control in overweight and obese adults with type 2 diabetes [24]. Recently Mattei, $\mathrm{Hu}$ and Campos found that higher reporting of bean consumption in comparison to white rice was associated with reduced cardiovascular disease risk based on food frequency data from Costa Rica [35]. Retention of traditional dietary patterns that include beans may be beneficial to health, reduce type 2 diabetes complications, and improve dietary adherence $[1,11,24]$.

An e-mail survey of Canadian dietitians found that $68 \%$ of those surveyed stated that they recommend legume consumption to individuals with diabetes, in comparison to the $87 \%$ who recommended legumes to individuals with known cardiovascular disease [36]. The American Diabetes Association recommends taking "into account personal and cultural preferences" as a goal for type 2 diabetes medical nutrition therapy [37]. However, it is not clear from the published literature whether culturally appropriate foods such as legumes are being recommended to individuals with diabetes in accordance with this goal. However, there is evidence in the public health literature of dissatisfaction or difficulty in adhering to the diabetic diet by ethnic and minority populations due to a lack of culturally appropriate recommendations with beans specifically cited as a valued part of meals and cultural identity [11-16].

Contrary to our hypothesis, the three $P$. vulgaris market classes exhibited significantly different levels of glycemic response. The pinto and black bean and rice combinations produced a lower glycemic response overall than the dark red kidney bean and rice meal despite the lower total fiber content of the black beans and the treatments being matched on available $\mathrm{CHO}$ content. The differences in 
calories, protein, and fat composition between the three bean/rice test meals are small. Woelver et al. have demonstrated that the carbohydrate content and GI of mixed meals is the central influence on glycemic response [38]. Therefore to explain differences in the observed responses variation in the specific fiber fractions of the three bean types may offer an explanation for the variation in glycemic response produced. There is some evidence that beans from the Andean center of domestication like dark red kidney may have lower levels of indigestible starch in comparison to beans with Mesoamerican origins like pinto and black. Lower levels of indigestible starch would speed up the digestion process of kidney beans in comparison to the other bean types [39]. In vitro animal evidence also indicates that red kidney beans have lesser amounts of soluble fiber and resistant starch than black beans. These components are known to slow digestion and therefore reduce postprandial glycemic response [40].

Phytochemicals and phytonutrients are associated with improvements in glycemic control [17]. These characteristics are likely to vary in the beans as well. In general, beans have high phytate levels which may bind to calcium, thus reducing it as a cofactor for $\alpha$-amylase enzyme activity [30]. Inhibition of $\alpha$-amylase by cooked beans has approximated that of acarbose, a popular diabetes medication [41]. Sievenpiper et al. reported in a meta-analysis that long term use of some beans normalized HbA1c almost as well as acarbose in two other meta-analysis reports [17]. Uncooked pinto beans were found to have higher levels of flavonoids than some other beans, and the sum of phenolic acids in the pinto beans was greater than chickpeas, split peas, lentils, and a variety of broad beans [42]. Data on black or red kidney beans were not reported. Pinto beans also reportedly contain high concentrations of antioxidants in comparison to chickpeas, and other non P.vulgaris species [43]. The observed differences in effect of the three beans highlights the importance of investigating multiple bean varieties rather than assuming all are the same. Further mechanistic work is needed on these specific varieties as well.

\section{Conclusion}

This study demonstrates that culturally relevant $P$. vulgaris species such as pinto, dark red kidney and black beans attenuate the glycemic response to rice, a commonly consumed high GI food. As healthcare practitioners, it is vital that we are culturally competent and sensitive to the needs of others who are different from us. Cultural competency is the "ability to discover the culture of each client/patient and effectively adapt interventions to her or him" [44]. Dietary recommendations, materials and counseling should be culturally sensitive and take into account valued traditional foods such as beans, especially when the scientific evidence supports their beneficial role in the diet.
Further research should be completed regarding the physical and chemical structure of various $P$. vulgaris bean types to attempt to address the observed differences in glycemic responses. While promoting traditional foods is a non-pharmacological way to manage type 2 diabetes, knowing which beans are most effective can help improve dietary adherence with an appropriate cultural twist.

\section{Abbreviations}

MANOVA: Multivariate analysis of variance; BMI: Body mass index; CHO: Carbohydrate; Gl: Glycemic index; HbA1c: Hemoglobin A1c; iAUC: incremental area under the curve.

\section{Competing interests}

The authors declare that they have no competing interests.

\section{Author's contributions}

DMW, AMH, SVT designed the research study. SVT conducted the majority of the data collection with assistance from DMW. SVT was responsible for data entry and preliminary analysis. SVT, DMW and AMH wrote the paper. DMW had primary responsibility for final content. All authors read and approved the final manuscript.

\section{Acknowledgements}

Funding for this project was provided in part by the United States Dry Bean Council and the Arizona State University Graduate \& Professional Student Association Research Support Program. Canned beans were donated by Bush Brothers \& Company, Knoxville, Tennessee.

\section{Author details}

${ }^{1}$ Center for Research on Occupational and Environmental Toxicology, Oregon Health and Science University, 3181 Southwest Sam Jackson Park Road, Portland, OR 97239, USA. ${ }^{2}$ Howell Research Associates, LLC, P.O. Box 1010, Queen Creek, AZ 85142, USA. ${ }^{3}$ Department of Health Sciences, University of Colorado at Colorado Springs, 1420 Austin Bluffs Parkway, Colorado Springs, CO 80918, USA.

Received: 19 October 2011 Accepted: 1 March 2012

Published: 11 April 2012

\section{References}

1. Leterme P: Recommendations by health organizations for pulse consumption. Br J Nutr 2002, 88(Suppl 3):S239-S242.

2. Darmadi-Blackberry I, Wahlqvist ML, Kouris-Blazos A, Steen B: Lukito W, Horie Y, Horie K: Legumes: the most important dietary predictor of survival in older people of different ethnicities. Asia Pac J Clin Nutr 2004, 13(2):217-220.

3. Bazzano LA, He J, Ogden LG, Loria C, Vupputuri S, Myers L, Whelton PK: Legume consumption and risk of coronary heart disease in US men and women. Arch Intern Med 2001, 161:2573-2578.

4. Centers for Disease Control and Prevention. National diabetes fact sheet: national estimates and general information on diabetes and prediabetes in the United States, 2011. Atlanta, GA: U.S. Department of Health and Human Services, Centers for Disease Control and Prevention, 2011.

5. O'Keefe JH, Bell DSH: Postprandial hyperglycemia/hyperlipidemia (postprandial dysmetabolism) is a cardiovascular risk factor. Am J Cardiol 2007, 100:899-904.

6. Eckel RH, Kahn R, Robertson RM, Rizza RA: Preventing cardiovascular disease and diabetes: A call to action from the American Diabetes Association and the American Heart Association. Diabetes Care 2006, 29:1697-1699.

7. Knowler WC, Barrett-Connor E, Fowler SE, Hamman RF, Lachin JM, Walker EQ, Nathan DM: Diabetes Prevention Program Research Group: Reduction in the incidence of type 2 diabetes with lifestyle intervention or metformin. N Engl I Med 2002, 346:393-403.

8. Herman WH, Hoerger TJ, Brandle M, Hicks K, Sorensen S, Zhang P, Hamman RF, Ackermann RT, Engelgau MM: Ratner RE and the Diabetes Prevention Program Research Group: The cost-effectiveness of lifestyle modification or metformin in preventing type 2 diabetes in adults with impaired glucose tolerance. Ann Intern Med 2005, 142:323-332. 
9. Knight KM, Dornant T, Bundy C: The diabetes educator: Trying hard, but must concentrate more on behaviour. Diabet Med 2006, 23:485-501

10. Vijan S, Stuart NS, Fitzgerald JT, Ronis DL, Hayward RA, Slater S, Hofer TP: Barriers to following dietary recommendation in type 2 diabetes. Diabet Med 2004, 22:32-38.

11. Caban A, Walker EA, Sanchez S, Mera MS: It feels like home when you eat rice and beans: perspectives of urban Latinos living with diabetes. Diabetes Spectrum 2008, 21(2):120-127.

12. Rustveld LO, Pavlik VN, Jibaja-Weiss ML, Kline KN, Gossey JT, Volk RJ: Adherence to diabetes self-care behaviors in English- and Spanish-speaking Hispanic Men. Patient Prefer Adherence 2009, 3:123-130.

13. Wen LK, Parchman ML, Shepherd MD: Family support and diet barriers among older Hispanic adults with type 2 diabetes. Fam Med 2004, 36:423-430

14. McCloskey J, Flenniken D: Overcoming cultural barriers to diabetes control: a qualitative study of southwestern New Mexico Hispanics. J Cult Divers 2010, 17:110-115.

15. Two Feathers J, Kieffer ED, Palmidano G, Anderson M, Soinco B, Janz N, Heisler M, Spencer M, Guzman R, Thompson J, Wisdom K, James SA: Racial and ethnic approaches to community health (REACH) Detroit partnership: improving diabetes-related outcomes among African Americans and Latino Adults. Am J Public Health 2005, 95:1552-1560.

16. de Groot M, Welch G, Buckland GT, Fergus M, Ruggiero L, Chipkin SR: Cultural orientation and diabetes self-care in low-income African Americans with type 2 diabetes mellitus. Ethn Dis 2003, 13:6-14.

17. Sievenpiper JL, Kendall CWC, Esfahani A, Wong JMW, Carleton AJ, Jiang HY, Bazinet RP, Vidgen E, Jenkins DJA: Effect of non-oil-seed pulses on glycaemic control: a systematic review and meta-analysis of randomized controlled experimental trials in people with and without diabetes. Diabetologia 2009, 52:1479-1495.

18. Brand-Miller J, Hayne S, Petocz P, Colagiuri S: Low-glycemic index diets in the management of diabetes: a meta-analysis of randomized controlled trials. Diabetes Care 2003, 26:2261-2267.

19. Bornet FRJ, Costagliola D, Rizkalla SW, Blayo A, Fontvieille AM, Haardt MJ, Letanoux M, Tchobroutsky G, Slama G: Insulinemic and glycemic indexes of six starch-rich foods taken alone and in a mixed meal by type 2 diabetics. Am J Clin Nutr 1987, 45:588-595.

20. Sugiyama M, Tang AC, Wakaki Y, Koyama W: Glycemic index of single and mixed meal foods among common Japanese foods with white rice as a reference food. Eur J Clin Nutr 2003, 57:743-752.

21. Ceriello A, Esposito K, Piconi L, Ihnat MA, Thorpe JE, Testa R, Boemi M, Giugliano D: Oscillating glucose is more deleterious to endothelial function and oxidative stress than mean glucose in normal and type 2 diabetic patients. Diabetes 2008, 57:1349-1354.

22. Sun Q, Spiegelman D, van Dam RM, Holmes MD, Malik VS, Willett WC, Hu FB: White rice, brown rice, and risk of type 2 diabetes in US men and women. Arch Intern Med 2010, 170:961-969.

23. Winham DM, Hutchins AM, Melde CL: Pinto bean, navy bean, and blackeyed pea consumption do not significantly lower the glycemic response to a high glycemic index treatment in normoglycemic adults. Nutr Res 2007, 27:535-541.

24. Jimenez-Cruz A, Bacardi-Gascón M, Turnbull WH, Rosales-Garay P, SeverinoLugo I: A flexible, low-glycemic index Mexican-style diet in overweight and obese subjects with type 2 diabetes improves metabolic parameters during a 6-week treatment period. Diabetes Care 2003, 26:1967-1970.

25. Venn BJ, Mann Jl: Cereal grains, legumes and diabetes. Eur $J$ Clin Nutr 2004, 58:1443-1461

26. Brand-Miller J, Foster-Powell K: Diets with a low glycemic index: from theory to practice. Nutrition Today 1999, 34(2):64-72

27. Foster-Powell K, Holt SHA, Brand-Miller JC: International table of glycemic index load values: 2002. Am J Clin Nutr 2002, 76(1):5-56.

28. Schakel S, Schauer R, Himes J, Harnack L, Van Heel N: Development of a glycemic index database for dietary assessment. J Food Compost Anal 2008, 21:S50-S55.

29. Asp NGL: Classification and methodology of food carbohydrates as related to nutritional effects. Am J Clin Nutr 1995, 61(Suppl):930S-937S.

30. Josse AR, Kendall CWC, Augustin LSA, Ellis PR, Jenkins DJA: Almonds and postprandial glycemia - a dose-response study. Metabolism 2007, 56:400-404
31. Panlasigui LN, Panlilio LM, Madrid JC: Glycaemic response in normal subjects to five different legumes commonly used in the Philippines. Int J Food Sci Nutr 1995, 46:155-160.

32. Sheng Duh M, Lefebvre P, Fastenau J, Tak Piech C, Waltzman RJ: Assessing the clinical benefits of erythropoietic agents using area under the hemoglobin change curve. Oncologist 2005, 10:438-448.

33. Cohen J: Statistical power analysis for the behavioral sciences. 2nd edition. Hillsdale, NJ: Lawrence Erlbaum; 1988

34. Ceriello A, Colagiuri S, Gerich J, Tuomilehto J: Guideline for management of postmeal glucose. Nutr Metab Cardiovasc Dis 2008, 18(4):S17-S33.

35. Mattei J, Hu FB, Campos H: A higher ratio of beans to white rice is associated with lower cardiometabolic risk factors in Costa Rican adults. Am J Clin Nutr 2011, 94:869-876.

36. Desrochers N, Brauer PM: Legume promotion in counseling: An e-mail survey of dietitians. Can J Diet Prac Res 2001, 62:193-198.

37. American Diabetes Association: Nutrition recommendations and interventions for diabetes: a position statement of the American Diabetes Association. Diabetes Care 2008, 31:S61-S78.

38. Wolever TMS, Yank M, Zeng XY, Atkinson F, Brand-Miller JC: Food glycemic index, as given by the Glycemic Index tables, is a significant determinant of glycemic responses elicited by composite breakfast meals. Am J Clin Nutr 2006, 83:1306-1312.

39. Ospina MT: Determination of dietary fiber, and total and indigestible starch and protein in a selected sample of dry bean (Phaseolus vulgaris L.) genotypes. Master of Science Thesis. Michigan State University, Nutrition Department; 2000.

40. Bednar GE, Patil AR, Murray SM, Grieshop CM, Merche NR, Fahey GC: Starch and fiber fractions in selected food and feed ingredients affect their small intestinal digestibility and fermentability and their large bowel fermentability in vitro in a canine model. J Nutr 2001, 131:276-286,

41. Helmstädter A: Beans and diabetes: Phaseolus vulgari preparations as antihyperglycemic agents. J Med Food 2010, 13:251-254.

42. Kalogeropoulos N, Chiou A, loannou M, Karathanos VT, Hassapidou M: Nutritional evaluation and bioactive microconstituents (phytosterols, tocopherols, polyphenols, triterpenic acids) in cooked dry legumes usually consumed in Mediterranean countries. Food Chem 2010, 121:682-690.

43. Halvorsen BL, Holte K, Myhrstad MCW, Barikmo I, Hvattum E, Remberg SF, Wold A, Haffner K, Baugerod H, Anderson LF, Moskaug JO, Jacobs DR, Blomhoff R: A systematic screening of total antioxidants in dietary plants. J Nutr 2002, 132:461-471

44. Curry K: Multicultural competence in dietetics and nutrition. J Am Diet Assoc 2000, 100(10):1142-1143.

doi:10.1186/1475-2891-11-23

Cite this article as: Thompson et al:: Bean and rice meals reduce postprandial glycemic response in adults with type 2 diabetes: a cross-over study. Nutrition Journal 2012 11:23.

\section{Submit your next manuscript to BioMed Central and take full advantage of:}

- Convenient online submission

- Thorough peer review

- No space constraints or color figure charges

- Immediate publication on acceptance

- Inclusion in PubMed, CAS, Scopus and Google Scholar

- Research which is freely available for redistribution 